\title{
PROFIL ANEMIA PADA PASIEN DIABETES MELLITUS PENDERITA NEFROPATI DIABETIK
}

Desyani Ariza1, Andi Ulfa Ferdhyanti², Ikhsan ${ }^{3}$

Email : desyaniariza@yahoo.co.id

1,2,3Program Studi DIV Teknologi Laboratorium Medik, Universitas MegaRezky Makassar, Indonesia

\section{ABSTRACT}

Diabetic nephropathy is one of the leading causes of kidney failure and the highest mortality among all complications of diabetes mellitus (DM). Anemia is the most common complication in DM patients, especially when accompanied by nephropathy or renal disorders. The purpose of this study was to see the Profile of Anemia in Diabetes Mellitus Patients with Diabetic Nephropathy. The methods used are descriptive and observational. The research was conducted during the period August - October 2020 which was conducted at the DR. Wahidin Sudirohusodo Hospital, Unhas Hospital and Antang Health Center. The number of research samples was 45 subjects who met the inclusion criteria, namely diabetic nephropathy patients. The anemia profile is determined from the results of routine hematology examinations by the Sysmex tool Series XN-1000 with the Flowcytometry method. The results of the study were obtained from 45 study subjects, it can be concluded that the most types of anemia based on the degree of anemia were very mild anemia category as many as 16 patients (35.5\%) and for the most types of anemia based on their morphology were 32 patients (71.1).

\section{ABSTRAK}

Nefropati diabetik adalah salah satu penyebab utama gagal ginjal dan kematian tertinggi diantara semua komplikasi diabetes mellitus. Anemia adalah komplikasi paling sering terjadi pada pasien DM, khususnya jika disertai dengan nefropati atau gangguan renal. Tujuan penelitian ini adalah untuk melihat Profil Anemia Pada Pasien Diabetes Mellitus Penderita Nefropati Diabetik. Metode yang digunakan yaitu Deskriptif dan Observasional. Penelitian dilakukan selama periode Agustus - Oktober 2020 yang dilakukan di Rumah Sakit DR. Wahidin Sudirohusodo, Rumah Sakit Unhas dan Puskesmas Antang. Jumlah sampel penelitian sebanyak 45 subyek yang memenuhi kriteria inklusi yaitu penderita nefropati diabetik. Profil anemia ditentukan dari hasil pemeriksaan hematologi rutin oleh alat Sysmex Series XN-1000 dengan metode alat Flowcytometry. Hasil penelitian diperoleh dari 45 subyek penelitian dapat disimpulkan bahwa jenis anemia terbanyak berdasarkan derajat anemianya adalah kategori anemia ringan sekali sebanyak 16 pasien $(35,5 \%)$ dan untuk jenis anemia terbanyak berdasarkan morfologinya adalah kategori anemia normositik normokrom sebanyak 32 pasien $(71,1)$.

\section{ARTICLE INFO}

Keywords:

Anemia, Diabetes Mellitus, Diabetic Nephropathy

DOI:

$\underline{10.24252 / \text { kesehatan.v14i2.16210 }}$

Kata kunci :

Anemia, Diabetes Mellitus, Nefropati Diabetik

\section{Pendahuluan}

Diabetes melitus (DM) adalah suatu kelompok penyakit metabolik dengan karakteristik hiperglikemia yang terjadi karena kelainan sekresi insulin, kerja insulin atau keduaduanya (ADA, 2015). Diabetes sering disebut sebagai the great imitator karena dapat mengenai semua organ tubuh. Salah satu organ yang menjadi target kerusakan utama adalah ginjal (Mogensen, 2009). Diantara komplikasi mikroangiopati, nefropati diabetik (ND) adalah satu yang paling serius. Sekitar 20-40\% penyandang diabetes akan mengalami nefropati diabetik (PERKENI, 2011) dan menjadi penyebab utama terjadinya penyakit gagal ginjal stadium akhir (Rodriguez, 2012). Kejadian anemia meningkat seiring dengan meningkatnya stadium ND dan penyakit ginjal kronis (Ito et al,2010). Hasil penelitian Hosseini et al menjelaskan bahwa terdapat hubungan antara anemia dengan Nefropati Diabetik. Prevalensi anemia lebih tinggi pada pasien Nefropati Diabetik dibandingkan non-Nefropati Diabetik (Hosseini et al, 2014). Berdasarkan uraian pembahasan diatas maka dikemukakan rumusan masalah sebagai berikut : Bagaimanakah Profil Anemia Pada Pasien Diabetes Mellitus Penderita Nefropati Diabetik?. Tujuan penelitian ini adalah untuk mengetahui Profil Anemia Pada Pasien Diabetes Mellitus Penderita Nefropati Diabetik. Manfaat penelitian ini adalah 
memberikan informasi mengenai profil aatau gambaran anemia pada pasien diabetes mellitus penderita nefropati diabetik sehingga pemeriksaan sejak dini bisa memberikan penanganan dan terapi yang tepat serta bisa pula mencegah tingkat keparahan terjadinya anemia apabila sudah dideteksi sejak dini.

\section{Metode Penelitian}

Jenis penelitian ini menggunakan Metode Deskriptif dan Observasional. Populasi penelitian ialah semua pasien rawat jalan yang didiagnosis menderita nefropati diabetik di Rumah Sakit Dr. Wahidin Sudirohusodo, Rumah Sakit Unhas dan Puskesmas Antang. Sampel penelitian adalah populasi terjangkau yang memenuhi kriteria penelitian dan diperoleh 45 subyek penelitian. Sampel penelitian diperoleh dari darah pasien dan dilakukan pemeriksaan hematologi rutin untuk melihat profil anemianya. Data yang diperoleh berupa data primer melalui pemeriksaan laboratorium, dan diolah menggunakan piranti SPSS untuk menyajikan data dalam bentuk tabel dan narasi.

\section{Kode Etik Kesehatan}

Persetujuan tindakan medik diperoleh dengan terlebih dahulu menjelaskan secara singkat latar belakaang, tujuan dan manfaat penelitian, serta tindakan pengambilan darah kepada pasien. Pasien kemudian menandatangani informed consent yang telah disiapkan. Ethical Clearance diperoleh dari Komisi Etik Penelitian Politeknik Kesehatan Makassar (Poltekes Makassar).

\section{Hasil Penelitian}

Penelitian ini diikuti oleh 45 subyek yang memenuhi kriteria inklusi dan berasal dari Rumah Sakit Dr. Wahidin Sudirohusodo, Rumah Sakit Unhas dan Puskesmas Antang. Penelitian dilaksanakan pada bulan Agustus - Oktober 2020.

Pada tabel 1 dapat dilihat karakteristik pasien menurut jenis kelamin, usia dan stadium nefropati diabetik. Dari hasil tabel 1 diperoleh menurut usia 21-40 tahun sebanyak 8 pasien $(17,8 \%)$, usia 41-60 tahun sebanyak 26 pasien $(57,8 \%)$ dan usia diatas 60 tahun sebanyak 11 pasien $(24,4 \%)$. Menurut jenis kelamin diperoleh jenis kelamin laki-laki sebanyak 26 pasien $(57,8 \%)$ dan jenis kelamin perempuan sebanyak 19 pasien $(42,2 \%)$. Menurut stadium nefropati diabetik diperoleh stadium 1 sebanyak 10 pasien $(22,2 \%)$, stadium 2 sebanyak 10 pasien (22,2\%), stadium 3 sebanyak 22 pasien $(48,9 \%)$ dan stadium 4 sebanyak 3 pasien $(6,7 \%)$.

Tabel 1. Profil Anemia Berdasarkan Karakteristik Pasien menurut Jenis kelamin, Usia dan Stadium Nefropati Diabetik

\begin{tabular}{cccc}
\hline \multicolumn{2}{c}{ Karakteristik } & $\mathrm{N}$ & $\%$ \\
\hline Usia & $21-40$ tahun & 8 & 17.8 \\
& $41-60$ tahun & 26 & 57.8 \\
& $>60$ tahun & 11 & 24.4 \\
Jenis Kelamin & Laki-laki & 26 & 57.8 \\
& Perempuan & 19 & 42.2 \\
Stadium & 1.00 & 10 & 22.2 \\
Nefropati & 2.00 & 10 & 22.2 \\
Diabetik & 3.00 & 22 & 48.9 \\
& 4.00 & 3 & 6.7 \\
\hline
\end{tabular}




\begin{tabular}{lcc}
\hline Jumlah & 45 & 100.0 \\
\hline
\end{tabular}

Pada tabel 2 dapat dilihat profil anemia berdasarkan nilai eritrosit pada stadium nefropati diabetik. Dari hasil tabel 2 menurut kategori nilai eritrosit rendah pada stadium 1 nefropati diabetik sebanyak 10 pasien (22,2\%), stadium 2 sebanyak 10 pasien $(22,2 \%)$, stadium 3 sebanyak 22 pasien (48,9\%) dan stadium 4 sebanyak 3 pasien $(6,7 \%)$.

\section{Tabel 2. Profil Anemia Berdasarkan Nilai Eritrosit Pada Stadium Nefropati} Diabetik

\begin{tabular}{cccccccc}
\hline \multirow{2}{*}{ Kategori } & & \multicolumn{7}{c}{ Stadium Nefropati Diabetik } & \multirow{2}{*}{ Jumlah } \\
\cline { 3 - 8 } & & 1 & 2 & 3 & 4 & \\
\hline \multirow{3}{*}{ Rendah } & $\mathrm{n}$ & 10 & 10 & 22 & 3 & 45 \\
\cline { 2 - 8 } & & $\%$ & $22.2 \%$ & $22.2 \%$ & $48,9 \%$ & $6.7 \%$ & $100.0 \%$ \\
\cline { 2 - 7 } Eritrosit & Normal & $\mathrm{n}$ & 0 & 0 & 0 & 0 & 0 \\
\cline { 2 - 7 } & & $\%$ & $0 \%$ & $0 \%$ & $0 \%$ & $0 \%$ & $0 \%$ \\
\cline { 2 - 7 } & Tinggi & $\mathrm{n}$ & 0 & 0 & 0 & 0 & 0 \\
\cline { 2 - 7 } & & $0 \%$ & $0 \%$ & $0 \%$ & $0 \%$ & $0 \%$ \\
\hline
\end{tabular}

Pada tabel 3 dapat dilihat profil anemia berdasarkan nilai hemoglobin pada stadium nefropati diabetik. Dari hasil tabel 3 menurut derajat anemia ringan sekali pada pasien nefropati diabetik stadium 1 diperoleh sebanyak 3 pasien $(6,7 \%)$, pada stadium 2 diperoleh sebanyak 2 pasien (4,4\%), pada stadium 3 diperoleh 10 pasien $(22,2 \%)$ dan stadium 4 sebanyak 1 pasien $(2,2 \%)$. Untuk darajat anemia ringan pada pasien nefropati diabetik stadium 1 diperoleh sebanyak 2 pasien (4,4\%), stadium 2 diperoleh sebanyak 5 pasien $(11,1 \%)$, stadium 3 diperoleh sebanyak 8 pasien $(17,8 \%)$ dan untuk stadium 4 tidak ditemukannya pasien nefropati diabetik dengan derajat anemia ringan $(0,0 \%)$. Untuk derajat anemia sedang pada pasien nefropati diabetik stadium 1 diperoleh sebanyak 3 pasien (6,7\%), pada stadium 2 diperoleh sebanyak 2 pasien $(4,4 \%)$, pada stadium 3 diperoleh sebanyak 3 pasien $(6,7 \%)$ dan stadium 4 diperoleh 1 pasien $(2,2 \%)$. Untuk derajat anemia berat pada nefropati diabetik stadium 1 diperoleh sebanyak 2 pasien (4,4\%), stadium 2 diperoleh 1 pasien $(2,2 \%)$, stadium 3 diperoleh 1 pasien $(2,2 \%)$ dan stadium 4 diperoleh 1 pasien $(2,2 \%)$.

Tabel 3. Profil Anemia Berdasarkan Nilai Hemoglobin Pada Stadium Nefropati Diabetik

\begin{tabular}{|c|c|c|c|c|c|c|c|}
\hline & \multirow{2}{*}{ Derajat } & & \multicolumn{4}{|c|}{ Stadium Nefropati Diabetik } & \multirow{2}{*}{ Jumlah } \\
\hline & & & 1 & 2 & 3 & 4 & \\
\hline \multirow{8}{*}{ Hemoglobin } & \multirow{2}{*}{$\begin{array}{c}\text { Anemia } \\
\text { Ringan } \\
\text { sekali }\end{array}$} & $\mathrm{n}$ & 3 & 2 & 10 & 1 & 16 \\
\hline & & $\%$ & $6.7 \%$ & $4.4 \%$ & $22.2 \%$ & $2.2 \%$ & $35.5 \%$ \\
\hline & \multirow{2}{*}{$\begin{array}{l}\text { Anemia } \\
\text { Ringan }\end{array}$} & $\mathrm{n}$ & 2 & 5 & 8 & 0 & 15 \\
\hline & & $\%$ & $4.4 \%$ & $11.1 \%$ & $17.8 \%$ & $0.0 \%$ & $33.3 \%$ \\
\hline & \multirow{2}{*}{$\begin{array}{l}\text { Anemia } \\
\text { Sedang }\end{array}$} & $\mathrm{n}$ & 3 & 2 & 3 & 1 & 9 \\
\hline & & $\%$ & $6.7 \%$ & $4.4 \%$ & $6.7 \%$ & $2.2 \%$ & $20.0 \%$ \\
\hline & \multirow{2}{*}{$\begin{array}{c}\text { Anemia } \\
\text { Berat }\end{array}$} & $\mathrm{n}$ & 2 & 1 & 1 & 1 & 5 \\
\hline & & $\%$ & $4.4 \%$ & $2.2 \%$ & $2.2 \%$ & $2.2 \%$ & $11.1 \%$ \\
\hline
\end{tabular}




\begin{tabular}{ccccccc}
\hline \multirow{3}{*}{ Jumlah } & $\mathrm{n}$ & 10 & 10 & 22 & 3 & $\mathbf{4 5}$ \\
\cline { 2 - 7 } & $\%$ & $22.2 \%$ & $22.2 \%$ & $48.9 \%$ & $6.7 \%$ & $\mathbf{1 0 0 . 0 \%}$ \\
\hline
\end{tabular}

Pada tabel 4 dapat dilihat profil anemia berdasarkan nilai hematokrit pada stadium nefropati diabetik. Dari hasil tabel 4 menurut kategori nilai hematokrit rendah pada nefropati diabetik stadium 1 diperoleh sebanyak 10 pasien $(22,2 \%)$, stadium 2 diperoleh sebanyak 10 pasien $(22,2 \%)$, stadium 3 diperoleh 22 pasien $(48,9 \%)$ dan stadium 4 diperoleh 3 pasien (6,7\%).

Tabel 4. Profil Anemia Berdasarkan Nilai Hematokrit Pada Stadium Nefropati Diabetik

\begin{tabular}{cccccccc}
\hline \multirow{2}{*}{ Kategori } & & \multicolumn{5}{c}{ Stadium Nefropati Diabetik } & \multirow{2}{*}{ Jumlah } \\
\cline { 3 - 8 } & & 1 & 2 & 3 & 4 & \\
\hline \multirow{3}{*}{ Rendah } & $\mathrm{n}$ & 10 & 10 & 22 & 3 & 45 \\
\cline { 2 - 8 } & $\%$ & $22.2 \%$ & $22.2 \%$ & $48,9 \%$ & $6.7 \%$ & $100.0 \%$ \\
\cline { 2 - 8 } & Normal & $\mathrm{n}$ & 0 & 0 & 0 & 0 & 0 \\
\cline { 2 - 8 } & & $\%$ & $0 \%$ & $0 \%$ & $0 \%$ & $0 \%$ & $0 \%$ \\
\cline { 2 - 8 } & Tinggi & $\mathrm{n}$ & 0 & 0 & 0 & 0 & 0 \\
\cline { 2 - 7 } & & $0 \%$ & $0 \%$ & $0 \%$ & $0 \%$ & $0 \%$ \\
\hline
\end{tabular}

Pada tabel 5 dapat dilihat profil anemia berdasarkan nilai indeks eritrosit pada stadium nefropati diabetik. Dari hasil tabel 5 menurut karakteristik morfologi anemia normositik normokrom pada pasien nefropati diabetik stadium 1 diperoleh sebanyak 8 pasien $(17,8 \%)$, pada stadium 2 diperoleh 4 pasien $(8,9 \%)$, stadium 3 diperoleh 19 pasien $(42,2 \%)$ dan stadium 4 diperoleh 1 pasien $(2,2 \%)$. Menurut karakteristik morfologi anemia normositik hipokrom pada pasien nefropati diabetik stadium 1 diperoleh sebanyak 1 pasien (2,2\%), stadium 2 diperoleh 1 pasien (2,2\%), stadium 3 tidak peroleh pasien nefropati diabetik yang mengalami anemia normositik hipokrom dan begitu pula pada stadium 4. Menurut karakteristik morfologi anemia normositik hiperkrom hanya ditemukan 1 pasien (2,2\%) pada nefropati diabetik stadium 2 . Menurut karakteristik morfologi anemia mikrositik normokrom pada pasien nefropati diabetik stadium 1 diperoleh 1 pasien (2,2\%), stadium 2 diperoleh 2 pasien $(4,4 \%)$, stadium 3 diperoleh 1 pasien (2,2\%) dan stadium 4 diperoleh 1 pasien (2,2\%). Menurut karakteristik morfologi anemia mikrositik hipokrom pada pasien nefropati diabetik hanya ditemukan pada stadium 2 yaitu sebanyak 2 pasien $(4,4 \%)$ dan stadium 3 sebanyak 2 pasien $(4,4 \%)$. Untuk karakteristik morfologi anemia makrositik hiperkrom diperoleh 1 pasien pada nefropati diabetik stadium 4. Untuk karakteristik morfologi anemia mikrositik hiperkrom, anemia makrositik normokrom dan anemia makrositik hipokrom tidak ditemukannya pasien yang mengalami kategori anemia tersebut.

Tabel 5. Profil Anemia Berdasarkan Nilai Indeks Eritrosit Pada Stadium Nefropati Diabetik

\begin{tabular}{|c|c|c|c|c|c|c|}
\hline \multirow{2}{*}{\multicolumn{2}{|c|}{$\begin{array}{c}\text { Anemia Berdasarkan } \\
\text { Morfologi }\end{array}$}} & \multicolumn{4}{|c|}{ Stadium Nefropati Diabetik } & \multirow{3}{*}{$\begin{array}{c}\text { Jumlah } \\
32\end{array}$} \\
\hline & & \multirow{2}{*}{$\begin{array}{l}1 \\
8\end{array}$} & \multirow{2}{*}{$\begin{array}{l}2 \\
4 \\
\end{array}$} & \multirow{2}{*}{$\begin{array}{c}3 \\
19\end{array}$} & \multirow{2}{*}{$\begin{array}{l}4 \\
1 \\
\end{array}$} & \\
\hline Normositik & $\mathrm{n}$ & & & & & \\
\hline Normokrom & $\%$ & $17.8 \%$ & $8.9 \%$ & $42.2 \%$ & $2.2 \%$ & $71.1 \%$ \\
\hline Normositik & $\mathrm{n}$ & 1 & 1 & 0 & 0 & 2 \\
\hline
\end{tabular}




\begin{tabular}{|c|c|c|c|c|c|c|}
\hline Hipokrom & $\%$ & $2.2 \%$ & $2.2 \%$ & $0.0 \%$ & $0.0 \%$ & $4.4 \%$ \\
\hline \multirow{2}{*}{$\begin{array}{l}\text { Normositik } \\
\text { Hiperkrom }\end{array}$} & $\mathrm{n}$ & 0 & 1 & 0 & 0 & 1 \\
\hline & $\%$ & $0.0 \%$ & $2.2 \%$ & $0.0 \%$ & $0.0 \%$ & $2.2 \%$ \\
\hline \multirow{2}{*}{$\begin{array}{c}\text { Mikrositik } \\
\text { Normokrom }\end{array}$} & $\mathrm{n}$ & 1 & 2 & 1 & 1 & 5 \\
\hline & $\%$ & $2.2 \%$ & $4.4 \%$ & $2.2 \%$ & $2.2 \%$ & $11.1 \%$ \\
\hline \multirow{2}{*}{$\begin{array}{l}\text { Mikrositik } \\
\text { Hipokrom }\end{array}$} & $\mathrm{n}$ & 0 & 2 & 2 & 0 & 4 \\
\hline & $\%$ & $0.0 \%$ & $4.4 \%$ & $4.4 \%$ & $0.0 \%$ & $8.8 \%$ \\
\hline \multirow{2}{*}{$\begin{array}{l}\text { Mikrositik } \\
\text { Hiperkrom }\end{array}$} & $\mathrm{n}$ & 0 & 0 & 0 & 0 & 0 \\
\hline & $\%$ & $0.0 \%$ & $0.0 \%$ & $0.0 \%$ & $0.0 \%$ & $0.0 \%$ \\
\hline \multirow{2}{*}{$\begin{array}{c}\text { Makrositik } \\
\text { Normokrom }\end{array}$} & $\mathrm{n}$ & 0 & 0 & 0 & 0 & 0 \\
\hline & $\%$ & $0.0 \%$ & $0.0 \%$ & $0.0 \%$ & $0.0 \%$ & $0.0 \%$ \\
\hline \multirow{2}{*}{$\begin{array}{l}\text { Makrositik } \\
\text { Hipokrom }\end{array}$} & $\mathrm{n}$ & 0 & 0 & 0 & 0 & 0 \\
\hline & $\%$ & $0.0 \%$ & $0.0 \%$ & $0.0 \%$ & $0.0 \%$ & $0.0 \%$ \\
\hline \multirow{2}{*}{$\begin{array}{l}\text { Makrositik } \\
\text { Hiperkrom }\end{array}$} & $\mathrm{n}$ & 0 & 0 & 0 & 1 & 1 \\
\hline & $\%$ & $0.0 \%$ & $0.0 \%$ & $0.0 \%$ & $2.2 \%$ & $2.2 \%$ \\
\hline \multirow{2}{*}{ Jumlah } & $\mathrm{n}$ & 10 & 10 & 22 & 3 & 45 \\
\hline & $\%$ & $22.2 \%$ & $22.2 \%$ & $48.9 \%$ & $6.7 \%$ & $100.0 \%$ \\
\hline
\end{tabular}

\section{Pembahasan}

Subjek penelitian ini sebanyak 45 pasien yang telah didiagnosis nefropati diabetik dan mengalami anemia berdasarkan hasil pemeriksaan hematologi rutin. Berdasarkan hasil penelitian ditemukan usia terbanyak pada sampel penelitian adalah 41-60 tahun yaitu sebanyak 26 pasien $(57,8 \%)$. Dari data tersebut ditemukan bahwa pertambahan umur turut berkontribusi terhadap kenaikan angka kejadian pasien diabetes mellitus penderita nefropati diabetik dikarenakan pertambahan umur menyebabkan penurunan fungsi organ dan metabolisme didalam tubuh. Menurut penelitian Gusti dan Ema (2014) menyatakan diabetes seringkali ditemukan pada masyarakat dengan usia yang sudah tua karena pada usia tersebut fungsi tubuh secara fisiologis semakin menurun dan terjadi penurunan sekresi atau resistensi insulin sehingga kemampuan fungsi tubuh untuk mengendalikan glukosa darah yang tinggi kurang optimal. Berdasarkan karakteristik jenis kelamin ditemukan jenis kelamin laki-laki $(57,8 \%)$ lebih banyak dibandingkan dengan perempuan $(42,2 \%)$. Hal ini disebabkan karena laki-laki biasanya mengkonsumsi rokok dan kurang mengontrol kadar glukosa darah sehingga lebih mempercepat terjadinya komplikasi pada DM khususnya ginjal karena kandungan rokok bisa menaikkan viskositas darah dan merusak saringan ginjal. Menurut Aisyah dkk (2015) menyatakan ada hubungan yang signifikan antara aktifitas merokok dengan kejadian gagal ginjal. Berdasarkan karakteristik profil anemia pada stadium nefropati diabetik ditemukan kategori stadium 3 merupakan yang terbanyak dengan jumlah 22 pasien $(48,9 \%)$. Hal ini disebabkan karena semakin meningkatnya derajat atau stadium nefropati maka semakin besar pula resiko mengalami anemia yang disebabkan karena semakin meningkatnya stadium nefropati akan mengindikasikan semakin besar pula kerusakan ginjal yang terjadi. Menurut Clara Adelia dkk (2015) menemukan bahwa prevalensi anemia pada DM tipe 2 dengan gangguan fungsi ginjal adalah $80 \%$ dari total sampel penelitiannya dan terbanyak pada pasien dengan gangguan ginjal. Berdasarkan profil anemia dengan melihat nilai eritrosit dan hematokrit ditemukan semua sampel penelitian mengalami penurunan jumlah eritrosit dan hematokrit dengan jumlah terbanyak pada stadium 3 yaitu 22 pasien $(48,9 \%)$. Hal ini disebabkan karena semua sampel penelitian mengalami anemia sehingga jumlah eritrosit dan hematokrit mengalami penurunan. Berdasarkan profil anemia menurut 
kategori derajat anemia diperoleh kategori anemia ringan sekali sebagai anemia terbanyak dengan jumlah 16 pasien $(35,5 \%)$. Pasien mengalami anemia ringan sekali karena rata-rata nilai hemoglobin menunjukkan range $10,00-13,00 \mathrm{gr} / \mathrm{dl}$ yang menunjukkan derajat anemia ringan sekali. Hal ini serupa dengan penelitian Putra Rahmadea dan Khairul Fuad (2018) yang menemukan $35 \%$ penderita diabetes komplikasi ginjal mengalami penurunan kadar hemoglobin dibawah kadar normal dengan rentang 10,1 - 11,0 gr/dl. Profil anemia berdasarkan morfologi anemia dengan menilai indeks eritrosit pada pasien nefropati diabetik ditemukan kategori anemia normositik normokrom dengan jumlah terbanyak yaitu 32 pasien (71,1\%). Anemia normositik normokrom adalah anemia dimana eritrosit memiliki ukuran dan bentuk yang normal. Sementara MCV, MCH dan MCHC juga dalam batas normal. Penyebab dari anemia jenis ini adalah hemolisis (anemia hemolitik), kehilangan darah akut, kegagalan sumsum tulang, gangguan endokrin dan gangguan ginjal. Penelitian ini serupa dengan Adhadi Isranurhaq tahun 2016 yang menemukan Berdasarkan kadar hemoglobin, MCV, MCH, dan RDW pasien gagal ginjal kronik menemukan jenis anemia terbanyak adalah normositik normokromik.

\section{Kesimpulan}

Berdasarkan hasil penelitian dapat disimpulkan bahwa jenis anemia terbanyak berdasarkan derajat anemianya adalah kategori anemia ringan sekali dan untuk jenis anemia terbanyak berdasarkan morfologinya adalah kategori anemia normositik normokrom.

\section{Daftar Pustaka}

1. ADA. Standards Of Medical Care In Diabetes. Diabetes Care :Volume.38, supplement 1, 2015. page S8-12, S58-60, S1-s93.

2. Mogensen, E.C. Choosing a Therapeutic Strategy To Reduce Serious Diabetic Complications : A Focus On Diabetic Nephropathy. Medical Department M, Aarus University Hospital, 2009 : 1-2.

3. PERKENI. Konsensus Pengelolaan dan pencegahan Diabetes Mellitus tipe2 di Indonesia. Jakarta, 2011.

4. Rodriguez D.L, Castelao A.M, Gorriz J.L, Alvaro F.D, Gonzalez J.F.N. Pathophysiological Role and Therapeutic Implications Of Inflammation in Diabetic Nephropathy. World J Diabetes,2012 ; 3 (1) : 7-18.

5. Ito $\mathrm{H}$ et al. Mild Anemia Is Frequent and Associate With Micro- and Macroangiopathies in Patients With Type 2 Diabetes Mellitus. Journal of Diabetes Investigation, 2010; 1:273-78.

6. Hosseini M.S et al. Anemia and Microvascular Complications in Patients With Type 2 Diabetes Mellitus. Nephro-Urology Monthly, 2014 ;6:1-7.

7. Gusti dan Ema. Hubungan Faktor Risiko Usia, Jenis Kelamin, Kegemukan dan Hipertensi dengan Kejadian Diabetes Mellitus Tipe 2 di Wilayah Kerja Puskesmas Mataram. Media Bina Ilmiah. 2014 : Vol.8 No.1 : 39-44

8. Aisyah, Hernawan AD, Ridha A. Perilaku Merokok Sebagai Faktor Yang Berisiko Terhadap Kejadian Gagal Ginjal Kronik. Epidemiology Fakultas Ilmu Kesehatan Universitas Muhammadiyah Pontianak. Jurnal Mahasiswa dan Peneliti Kesehatan. 2015 : p.81

9. Wijaya CA, Kusnadi Y, Zen NF. Korelasi Antara Kadar Hemoglobin dan Gangguan Fungsi Ginjal Pada Diabetes Mellitus Tipe 2 di RSUP dr Mohammad Hoesin Palembang. MKS, Th.47, No.1, Januari 2015 : p. 43

10. Utami PR, Fuad K. Gambaran Kadar Hemoglobin Pada Penderita Diabetes Mellitus Komplikasi Ginjal. Jurnal Kesehatan Perintis. Volume 5 Nomor 1 Tahun 2018 : p.128 
11. Isranurhaq, Adhadi. Profil Anemia Pada Pasien Penyakit Ginjal Kronik Di RSUP DR. Wahidin Sudirohusodo. Fakultas Kedokteran Universitas Hasanuddin, Makassar. 2016.p. 62-63 